\title{
Biodiversitas Mangrove di Pulau Mansuar Kabupaten Raja Ampat Provinsi Papua Barat \\ (The Biodiversity of Mangrove in the Mansuar Island Raja Ampat District West Papua Province)
}

\author{
Troce Mayor ${ }^{1)}$, Herny E.I. Simbala2), Roni Koneri ${ }^{*}$ ) \\ 1) Program Studi Biologi, Jurusan Biologi FMIPA UNSRAT Manado, 95115 \\ 2) Program Studi Farmasi FMIPA UNSRAT Manado, 95115 \\ *Email korespondensi: ronicaniago@unsrat.ac.id
}

Diterima 27 Juli 2017, diterima untuk dipublikasikan 8 Agustus 2017

\begin{abstract}
Abstrak
Hutan mangrove merupakan formasi hutan yang tumbuh dan berkembang pada daerah landai di muara sungai dan pesisir pantai yang dipengaruhi oleh pasang surut air laut dan pantai berlumpur. Penelitian ini bertujuan untuk menganalisis biodiversitas mangrove di Pulau Mansuar Kabupaten Raja Ampat, Provinsi Papua Barat. Metode yang digunakan yaitu transek kuadrat. Hasil penelitian ditemukan sebanyak 6 famili 11 spesies dan 554 individu mangrove. Komposisi individu tertinggi dimiliki oleh spesies Rhizophora apiculata, sedangkan terendah yaitu spesies Xylocarpus rumpii. Indeks keanekaragaman, kekayaan, dan kelimpahan spesies mangrove pada semua tingkat pertumbuhan tertinggi pada stasiun 3, sedangkan terendah pada stasiun 1. Berdasarkan besaran kriteria yang dikemukakan oleh Shannon-Weiner maka indeks keanekaragaman mangrove di Pantai Yenbubua, Kepulauan Mansuar tergolong kategori sedang.

Kata kunci: biodiversitas, kekayaan spesies, Pulau Mansuar, Rhizophora apiculata.
\end{abstract}

\begin{abstract}
Mangrove forests are forest formations that grow and flourish in slopes at the mouth of the rivers and coastal areas that are affected by tidal sea water and muddy beaches. This study aimed to analyze the biodiversity of mangroves in Mansuar Island, Raja Ampat District, West Papua Province. The method used was quadrat transects. The results of the study showed that there were 6 families of 11 species and 554 individuals. The highest composition of the individual mangrove species was Rhizophora apiculata, while the lowest composition was Xylocarpus rumpii. The highest diversity index, richness, and abudance spesies in a various growth rate were observed in the station 3, while these lowest parameters were found in the station 1. Based on the magnitude of the criteria proposed by Shannon-Weiner, the index of mangrove diversity in Yenbubua Beach, Mansuar Islands was classified as medium category.

Keywords: biodiversity, Mansuar Island, Rhizophora apiculata, species richness

\section{PENDAHULUAN}

Kepulauan Mios Mansuar merupakan gugusan dari Pulau Raja Ampat yang terletak di Provinsi Papua Barat. Ekosistem yang ada di daerah pesisir Pulau Mansuar memiliki keanekaragaman hayati yang

beranekaragam seperti vegetasi lahan perkebunan, terumbu karang, lamun, dan hutan mangrove. Hutan mangrove menjadi bagian dari ekosistem lingkungan hidup di Pulau Mios Mansuar.
\end{abstract}


Luas hutan mangrove di dunia 15,9 juta ha dan $27 \%$ atau seluas 4,25 juta ha terdapat di Indonesia (Arobaya dan Wanma 2006). Luasan ini penyebarannya hampir di seluruh wilayah Indonesia dengan penyebaran terluas di Papua. Luas hutan mangrove di Papua sekitar 1.326 .990 ha atau $30 \%$ dari luas hutan mangrove yang terdapat di Indonesia (Paramudji 2010).

Mangrove merupakan ekosistem yang berada pada wilayah intertidal, yang mana pada wilayah tersebut terjadi interaksi antara perairan laut, payau, sungai dan terestrial. Interaksi ini menjadikan ekosistem mangrove mempunyai keanekaragaman yang tinggi baik berupa flora maupun fauna (Sengupta 2010). Ekosistem mangrove merupakan mata rantai utama yang berperan sebagai produsen dalam jaring makanan ekosistem pantai. Ekosistem ini memiliki produktivitas yang tinggi dengan menyediakan makanan berlimpah bagi berbagai jenis hewan laut dan menyediakan tempat berkembang biak, memijah, dan membesarkan anak bagi beberapa jenis ikan, kerang, kepiting, dan udang. Berbagai jenis ikan baik yang bersifat herbivora, omnivora maupun karnivora hidup mencari makan di sekitar mangrove terutama pada waktu air pasang (Gunarto 2004).

Keberadaan hutan mangrove di Kepulaua Mansuar sekarang ini cukup mengkhawatirkan karena adanya alih fungsi hutan mangrove menjadi permukiman, ataupun tempat wisata. Adanya aktivitas penebangan hutan mangove secara legal maupun ilegal di pesisir mampu menurunkan populasi mangrove hingga lebih dari $50 \%$ dalam kurun waktu 30 tahun (Sulistyawati 2009). Pemanfaatan kawasan mangrove yang terus menerus dilakukan berpotensi mereduksi keanekaragaman spesies tumbuhan yang memiliki peran dan fungsi utama secara ekologis dan potensial untuk dimanfaatkan secara sosial ekonomi. Secara ekologis hutan mangrove berperan penting dalam melindungi abrasi, tsunami dan intrusi air laut (Thampanya et al. 2006) serta sebagai habitat penting bagi berbagi organisme teresterial dan perairan (Skilleter dan Warren 2000).

Selain hal tersebut, tingginya aktifitas masyarakat di darat maupun di laut akan menghasilkan produk sampingan yang tidak bisa di hindari seperti limbah, sampah dan lumpur yang juga memberikan kontribusi terhadap lingkungan pesisir serta degradasi mangrove baik secara langsung maupun tidak langsung. Penelitian ini bertujuan untuk menganalisis biodiversitas mangrove di Kepulauan Mansuar Kabupaten Raja Ampat, Provinsi Papua Barat.

\section{METODE}

Penelitian dilaksanakan pada bulan Desember 2016 sampai Juli 2017. Lokasi penelitian dilakukan di kawasan hutan mangrove di Pantai Yenbuba Pulau Mansuar Kabupaten Raja Ampat, Provinsi Papua Barat (Gambar 1). Lokasi pengambilan sampel dibagi atas 3 stasiun berdasarkan kondisi habitat dan aktivitas masyarakat di sekitar kawasan hutan mangrove yaitu: dekat pemukiman masyarakat (stasiun 1), muara sungai (stasiun 2) dan dekat hutan (stasiun 3) (Gambar 1).

\section{Teknik Pengambilan Sampel}

Pengambilan data vegetasi tumbuhan mangrove dilakukan dengan cara transek kuadrat (Oosting 1956). Masing-masing stasiun dibuat 3 transek dan pada setiap transek diletakkan 3 plot. Pada setiap garis transek dibuat plot dengan ukuran 10 x10 m (untuk klasifikasi pohon: $\varnothing>10$ $\mathrm{cm}$ ), plot ukuran $5 \mathrm{~m} \times 5 \mathrm{~m}$ untuk pengukuran klasifikasi pancang $(4 \mathrm{~cm}$ $<\varnothing<10 \mathrm{~cm}$ ) dan plot ukuran $1 \mathrm{~m} \times 1 \mathrm{~m}$ untuk klasifikasi semai $(\varnothing<4 \mathrm{~cm}$ ). Semua jenis tumbuhan mangrove 


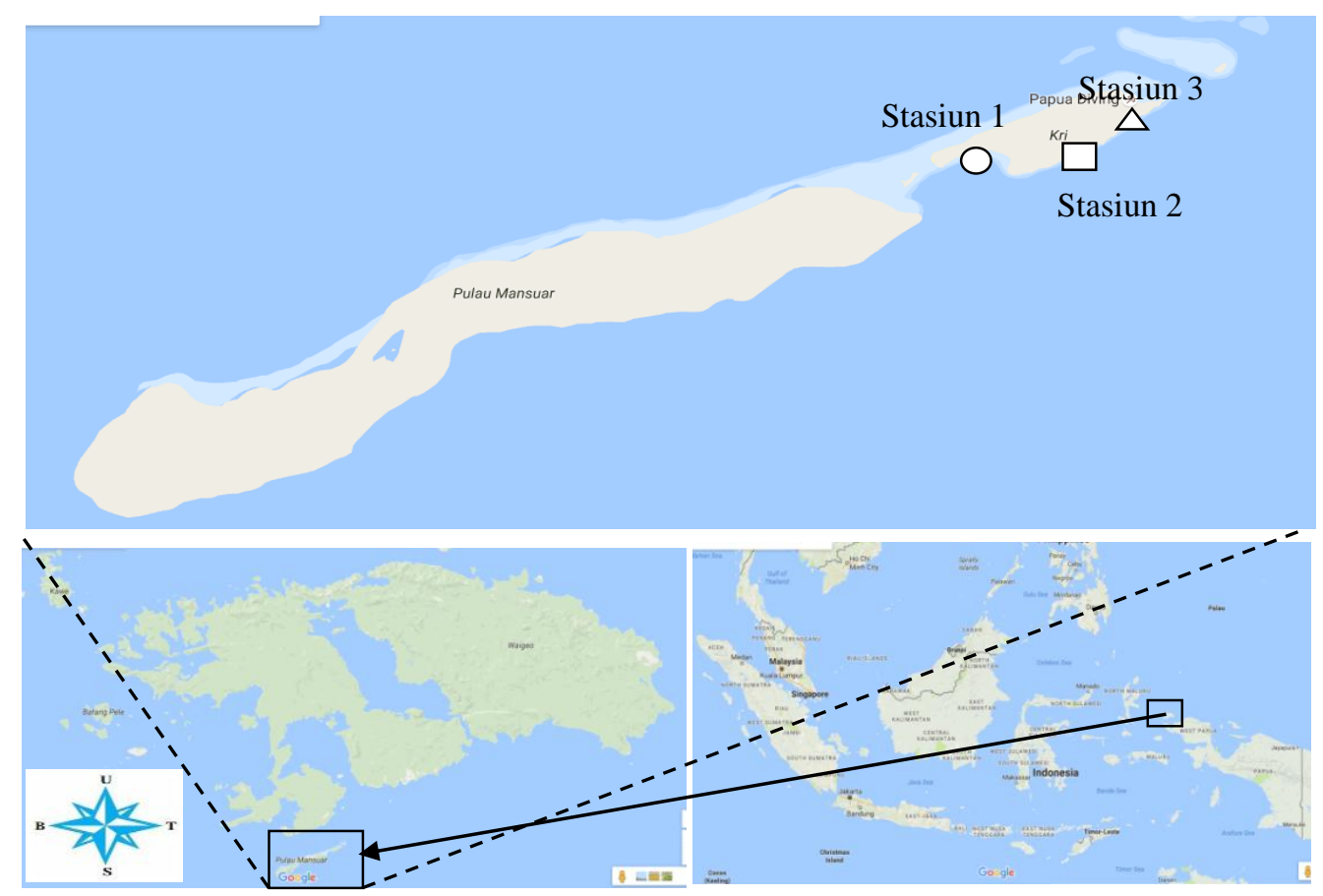

Gambar 1. Peta lokasi penelitian

\section{Analisis Data}

Analisa data meliputi indeks keanekaragaman spesies, kekayaan spesies dan kelimpahan spesies. Indeks keanekaragaman spesies menggunakan rumus keanekaragaman oleh ShannonWienner (Stiling 1992) sebagai berikut:

$$
\mathrm{H}^{\prime}=-\sum_{i=1}^{\mathrm{s}} \text { (pi)(lnpi) }
$$

Dimana $\mathrm{pi}=\mathrm{ni} / \mathrm{N} ; \mathrm{ni}=$ jumlah individu suatu jenis; $\mathrm{N}=$ jumlah total individu jenis;

$\mathrm{pi}=$ proporsi jumlah individu suatu jenis ke-1 dan $\mathrm{S}=$ jumlah jenis

yang terdapat pada plot dicatat dan diidentifikasi, sedangkan untuk jenis tumbuhan yang belum dapat diidentifikasi di lapang akan diambil spesimennya, difoto, kemudian akan diidentifikasi dengan menggunakan buku identifikasi dari Pramudji (2009) dan Kusmana (2003).
HASIL DAN PEMBAHASAN Komposisisi Spesies Mangrove

Berdasarkan hasil penelitian pada 3 stasiun didapatkan sebanyak 6 famili, 11 spesies dan 554 individu mangrove (Tabel 1). Hasil penelitian ini lebih rendah jika dibandingkan dengan penelitian yang pernah dilakukan di Teluk Bintuni yang menemukan sebanyak 12 spesies dalam kawasan mangrove seluas 137.000 ha dan hasil survei inventarisasi terdapat 57 jenis mangrove, di Kabupaten Raja Ampat (Kusmana et al. 2003).

Vegetasi mangrove mayor yang ditemukan selama penelitian sebanyak 7 spesies, di antaranya Rhizophora apiculata, Rhizophora mucronata, Sonneratia alba, Bruguiera gymnorhiza, Ceriops decandra, Lumnitzera littorea, Aegiceras corniculatum. Vegetasi mangrove minor sebanyak 2 jenis, yaitu Xylocarpus moluccensis dan Xylocarpus rumphi, sedangkan kategori mangrove asosiasi terdiri dari Scaveola taccada dan Terminalia 
catappa. Tomlinson (1986) melaporkan bahwa jika kategori mangrove mayor mampu membentuk tegakan murni dan mensekresikan air garam sehingga dapat tumbuh pada air tergenang, mangrove minor tumbuh pada tepi habitat mangrove dan tidak membentuk tegakan murni, sementara itu asosiasi mangrove cenderung hanya tumbuh pada habitat teresterial.

\section{Distribusi}

penyebaran

mangrove pada ketiga stasiun berbeda-beda. Stasiun 3 merupakan lokasi yang ditemukan semua spesies (11 spesies) dan yang paling sedikit pada stasiun 1 yang hanya ditemukan 5 spesies. Spesies yang penyebarannya merata yaitu ditemukan pada semua lokasi penelitian terdiri dari 5 spesies yaitu Rhizophora apiculata, Rhizophora mucronata, Sonneratia alba, Bruguiera gymnorhiza, Ceriops decandra, dan Soneratia alba. Xylocarpus moluccensis merupakan spesies yang ditemukan pada dua lokasi (stasiun 2 dan 3). Spesies yang hanya ditemukan pada satu lokasi (staiun 3) teriri dari 5 spesies diantaranya Lumnitzera littorea, Terminalia cattapa, Scaveola taccada, Xylocarpus rumphi, dan Aegiceras corniculatum (Tabel 1).

Distribusi mangrove pada suatu ekosistem sangat tergantung dengan adaptasi spesies mangrove tersebut. Menurut Bengen (2001) adaptasi fisiologis mangrove dilakukan dengan cara: (1) pada kadar Oksigen rendah dengan membentuk perakaran yang memiliki pneumatophora (seperti Avicennia spp; Xylocarpus sp. dan Sonneratia spp) serta lentisel (seperti Rhizophora spp), (2) konsentrasi garam tinggi dengan memiliki stomata khusus untuk mengurangi penguapan, daun yang kuat dan tebal dan sel-sel khusus pada daun untuk menyimpan garam (3) stabilitas tanah dan kondisi pasang surut dengan mengembangkan struktur perakaran esktensif yang berfungsi memperkokoh, mengambil unsur hara serta menahan sedimen.
Famili yang paling banyak ditemukan jumlah spesiesnya adalah Rhizophoraceae (4 spesies), sedangkan yang paling sedikit adalah Lythraceae yang hanya satu spesies. Beberapa penelitian melaporkan bahwa Rhizophoraceae merupakan famili yang spesiesnya dominan ditemukan (Heriyanto dan Subiandono 2012, Hidayatullah dan Pujiono 2014). Meratanya penyebaran dari Rhizophoraceae karena Rhizophoraceae dari jenis Rhizophoa mucronata Lmk dan Bruguiera sangat baik dalam memanfaatkan energi matahari, unsur hara/mineral dan air serta sifat kompetesi sehingga mendominasi jenis-jenis lainnya.

Famili Rhizophoraceae dapat beradaptasi dengan faktor-faktor lingkungan lebih baik bila dibandingkan dengan jenis lain (Silaen et al. 2013). Rhizophora sp juga mempunyai sebaran yang merata karena bersifat vivipar, yaitu kondisi yang mana biji mampu berkecambah semasa buah masih melekat pada pohon induknya. Adaptasi mangrove yang tinggi terutama pada jenis tertentu seperti propagul pada jenis Rhizophora sp umumnya telah tumbuh sejak masih menempel pada batang induknya (vivipar) sehingga tingkat keberhasilan pertumbuhan menjadi lebih besar. $R$. mucronata juga memiliki bentuk propagul yang jauh lebih besar dengan cadangan makanan yang lebih banyak, sehingga memiliki kesempatan hidup lebih tinggi dan dapat disebarkan oleh arus air laut secara lebih luas.

\section{Indeks Keanekaragaman, Kekayaan dan Kelimpahan Spesies Mangrove} Keanekaragaman spesies mangrove pada tingkat semai tertinggi ditemukan pada stasiun $3(\mathrm{H}=1,52)$, sedangkan yang terendah pada stasiun $1(H=1,29)$. Hal yang sama juga terjadi pada mangrove pada tingkat pancang dan pohon yang mana indeks keanekaragaman tertinggi ditemukan pada stasiun 3 (Gambar 
2a). Berdasarkan besaran kriteria yang dikemukakan oleh Shannon- Weiner yaitu $H^{\prime}<1$ kategori Rendah, $H^{\prime}$ 1-3 kategori Sedang dan H' $3>$ kategori Tinggi, sehinga berdasarkan pengklasifikasian di atas maka keanekaragaman mangrove di Pantai Yenbubua merupakan kategori Sedang.
Kekayaan spesies menujukkan jumlah spesies mangrove yang ditemukan selama penelitian. Berdasarkan lokasi penelitian didapatkan bahwa pada tingkat semai, pancang dan pohon kekayaan spesies tertinggi pada stasiun 3 , sedangkan jumlah spesies yang ditemukan paling sedikit pada stasiun 1 (Gambar 2b).

Tabel 1. Jumlah famili, spesies pada lokasi yang dekat pemukiman masyarakat (St1), muara sungai (St2), dan jauh dari pemukiman (St3).

\begin{tabular}{lllrrrrr}
\hline Famili & Spesies & Nama Lokal & ST 1 & ST2 & ST 3 & Jumlah & \% \\
\hline Rhizophoraceae & Rhizophora apiculata & Kor-kor & 67.00 & 42.00 & 125.00 & 234.00 & 42.24 \\
& Ceriops decandra & Parem & 3.00 & 61.00 & 30.00 & 94.00 & 16.97 \\
& Bruguiera gymnorhiza & Aiwon & 21.00 & 40.00 & 32.00 & 93.00 & 16.79 \\
& Rhizophora Mucronata & Kor-kor & 1.00 & 35.00 & 1.00 & 37.00 & 6.68 \\
Lythraceae & Sonneratia alba & Twai/ Tawawir & 50.00 & 11.00 & 13.00 & 74.00 & 13.36 \\
Combretaceae & Lumnitzera littorea & Pararuyek & 0.00 & 0.00 & 9.00 & 9.00 & 1.62 \\
& Terminalia cattapa & Krit & 0.00 & 0.00 & 3.00 & 3.00 & 0.54 \\
Goodeniaceae & Scaveola taccada & Aianat & 0.00 & 0.00 & 4.00 & 4.00 & 0.72 \\
Meliaceaea & Xylocarpus moluccensis & Awaiyou & 0.00 & 1.00 & 2.00 & 3.00 & 0.54 \\
& Xylocarpus rumphii & Awaiyou & 0.00 & 0.00 & 1.00 & 1.00 & 0.18 \\
Myrsinaceae & Aegiceras corniculatum & Mankrin -krin & 0.00 & 0.00 & 2.00 & 2.00 & 0.36 \\
\hline Total & & & $\mathbf{1 4 2 . 0 0}$ & $\mathbf{1 9 0 . 0 0}$ & $\mathbf{2 2 2 . 0 0}$ & $\mathbf{5 5 4 . 0 0}$ & $\mathbf{1 0 0 . 0 0}$ \\
\hline
\end{tabular}
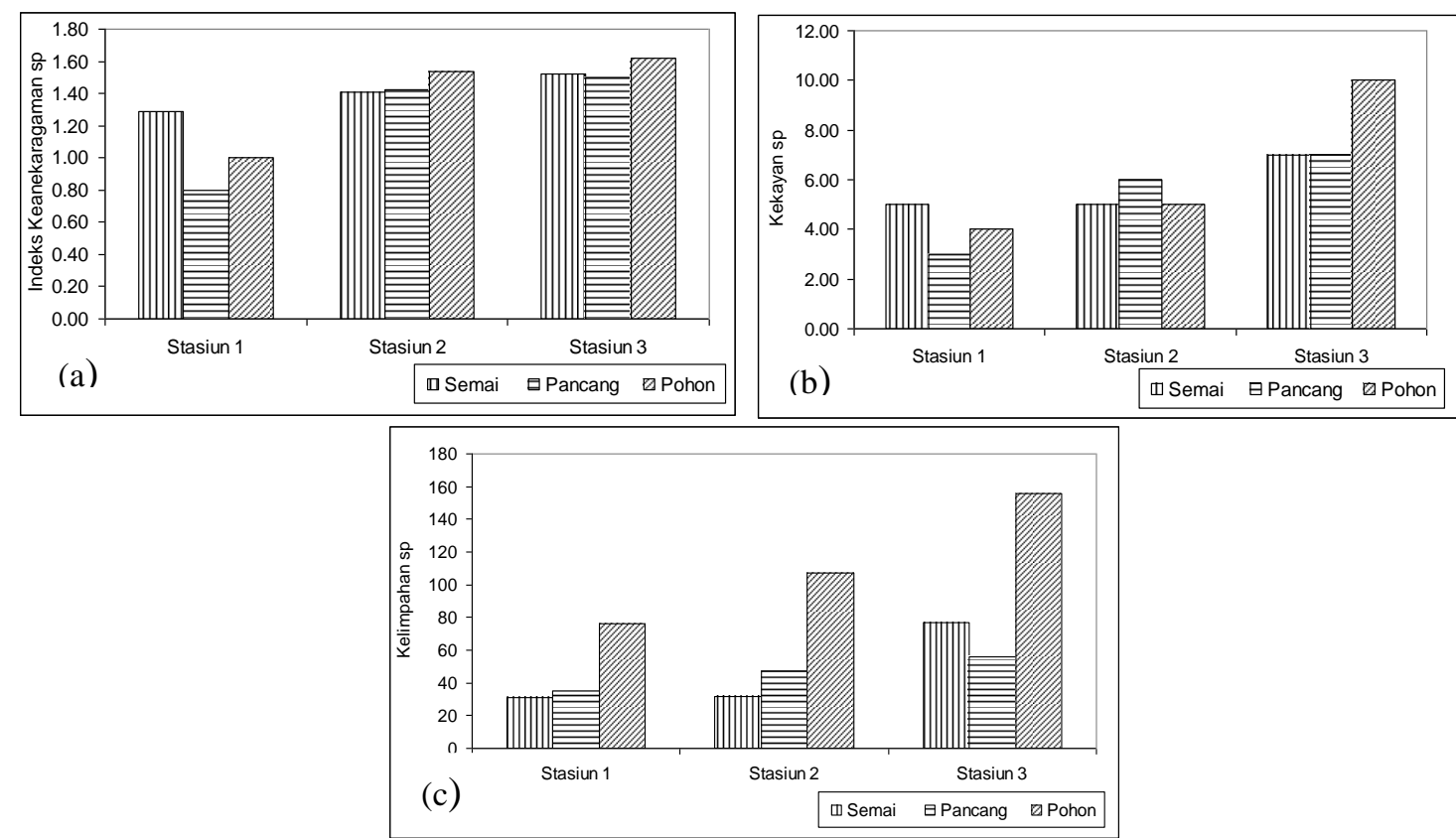

Gambar 2. (a) Indeks Kenekaragaman spesies, (b) kekayaan spesies dan (c) kelimpahan spesies mangrove pada tiga stasiun pengamatan di Pantai Yenbuba Pulau Mansuar. 


\section{JURNAL BIOSLOGOS, AGUSTUS 2017, VOL. 7 NOMOR 2}

Kelimpahan

spesies menunjukkan jumlah individu spesies mangrove yang ditemukan pada lokasi penelitian. Hasil penelitian menunjukkan bahwa kelimpahan spesies pada tingkat semai, pancang dan pohon tertinggi ditemukan pada stasiun 3, sedangkan yang terendah pada stasiun 1 (Gambar 2c). Jumlah individu mangrove sangat tergantung dengan kondisi habitat dan aktivitas manusia.

$$
\text { Tingginya }
$$

indeks

keanekaragaman spesies pada stasiun 3 karena lokasi penelitian ini terletak pada kawasan yang jauh dari pemukiman dan jarang mendapat gangguan dari manusia. Nilai indeks keanekaragaman menggambarkan enis keanekaragaman tingkat Bila nilai keanekaragaman semakin tinggi maka semakin meningkat keanekaragamanya dalam tegakan tersebut. Heriyanto dan Garsetiasih (2004) menyatakan bahwa keranekaragaman spesies cenderung menjadi tinggi di dalam komunitas yang lebih tua dan rendah di dalam komunitas yang baru terbentuk. Soeroyo dan Suyarso (2000) menambahkan bahwa kemantapan habitat merupakan faktor utama yang mengatur keanekaragaman spesies. Kondisi pantai pada stasiun 3 juga mendukung kenaekaragaman spesies yaitu dengan pantai yang landai dan kurang mendapat pukulan dari ombak. Ekosistem mangrove juga memiliki produktivitas primer yang tinggi namun dapat dengan mudah berubah bila ada gangguan terutama yang bersifat antropogenik (Hogart 1998, Walter et al. 2008).

Keanekaragaman jenis mangrove dipengaruhi oleh faktor lingkungan fisik yaitu jenis tanah, terpaaan ombak, dan penggenangan oleh air pasang (Arief 2003). Selain itu, keanekaragaman jenis pada vegetasi mangrove juga berdasarkan pada tempat tumbuhnya dan dibedakan dalam beberapa zonasi. Faktor lingkungan yang turut mempengaruhi terjadinya pertumbuhan diantaranya adalah suplai air tawar dan salinitas, stabilitas substrat, pasokan nutrien (Dahuri 2003). Irwanto (2006) bahwa rendahnya keanekaragaman menandakan ekosistem mengalami tekanan atau kondisinya mengalami penurunan, ini bisa disebabkan karena mangrove hidup pada tingkatan ekstrim seperti kadar garam yang tinggi serta subtrat yang berlumpur. Oleh karena itu untuk dapat hidup harus melalui seleksi yang sangat ketat dan daya adaptasi yang tinggi.

Rendahnya jumlah spesies yang ditemukan pada stasiun 1 disebabkan oleh aktifitas manusia. Hal ini bisa dilihat dari aktifitas penebangan, pemanfaatan lokasi sekitar mangrove sebagai dermaga perahu nelayan dan reklamasi pantai. Setyawan et al. (2005) menyatakan sedikitnya jumlah spesies mangrove disebabkan besarnya pengaruh antropogenik yang mengubah habitat mangrove untuk kepentingan lain.

Kelimpahan spesies pada kategori semai sangat sangat jarang ditemukan terutama pada stasiun satu yang dekat dengan pemukiman. Hal ini dipengaruhi oleh sampah dan tumpukan kayu yang dibuang oleh masyarakat di sekitar hutan mangrove. Menurut Pramudji (2009) adanya tumpukan kayu yang terhampar di kawasan hutan mangrove sehingga mempengaruhi pertumbuhan dan perkembangan semai dari mangrove.

\section{KESIMPULAN}

Jumlah famili mangrove yang ditemukan sebanyak 6 famili yang meliputi 11 spesies dan 554 individu mangrove. Famili yang paling banyak ditemukan jumlah spesiesnya adalah Rhizophoraceae, sedangkan yang paling sedikit adalah Lythraceae yang 
hanya satu spesies. Keanekaragaman spesies mangrove pada tingkat semai, pancang dan pohon tertinggi ditemukan pada stasiun 3 , sedangkan yang terendah pada stasiun 1. Indeks keanekaragaman mangrove di Pantai Yenbubua, Kepulauan Mansuar tergolong kategori Sedang berdasarkan besaran kriteria yang dikemukakan oleh Shannon-Weiner. Kekayaan dan kelimpahan spesies mangrove pada tingkat semai, pancang dan pohon tertinggi pada stasiun 3, sedangkan yang paling sedikit pada stasiun 1 .

\section{DAFTAR PUSTAKA}

Arief A (2003). Fungsi dan manfaat hutan mangrove. Kanisius, Yogyakarta.

Arobaya A, Wanma, A (2006) Menelusuri Sisa areal hutan mangrove di Manokwari. Warta Konservasi Lahan Basah 14 (4): 4-5

Bengen DG (2001) Pedoman teknis pengenalan dan pengelolaan ekosistem mangrove. PKSPL. IPB, Bogor

Dahuri R (2003) Keanekaragaman hayati laut, aset pembangunan berkelanjutan Indonesia. Gramedia Pustaka Utama, Jakarta

Gunarto (2004) Konservasi mangrove sebagai pendukung sumber hayati perikanan pantai. Jurnal Litbang Pertanian 23 (1).

Heriyanto NM, Garsetiasih R (2004) Potensi pohon kulim (Scorodocarpus borneensis Becc) di kelompok Hutan Gelawan Kampar Riau. Buletin Plasma Nutfah 10(1): 37-41.

Heriyanto NM, dan Subiandono $E$ (2012) Komposisi dan struktur tegakan, biomasa, dan potensi Kandungan karbon hutan mangrove di Taman Nasional Alas Purwo. Jurnal Penelitian Hutan dan Konervasi Alam 9 (1): 023-032
Hidayatullah M, Pujiono E (2014) Struktur dan komposisi jenis hutan mangrove di Golosepang-Kecamatan Boleng Kabupaten Manggarai Barat. Jurnal Penelitian Kehutanan Wallacea 3 (2):151162

Hogart JP (1998). The biology of mangrove and sea grass. Second Edition. Oxford University Press, UK

Irwanto (2006) Keanekaragaman fauna pada ekosistem mangrove.

www.irwantoshut.com. Diakses pada 12 Maret 2010

Kusmana C, Onrizal , Suadarmadji (2003) Jenis-jenis pohon mangrove di Teluk Bintuni.

Fakultas Kehutanan Institut Pertanian Bogor dan PT. Bintuni Utama Murni Wood Industries

Oosting (1956) The study of plant community. Freeman and Company. London

Pramudji (2009) Mangrove. Lembaga IImu Pengetahuan Indonesia Pusat Penelitian Oseanografi, Jakarta

Sengupta R (2010) Mangrove soldiers of our coasts. Mangrove for The Future India, 20, Anand Lok, August Kranti Marg, India

Setyawan AD, Indrowuryatno, Wiryanto K, Winarno, dan Susilowati A (2005) Tumbuhan mangrove di pesisir Jawa Tengah: Komposisi dan struktur vegetasi. Biodiversitas 6 (3): 19

Silaen IFB, Hendrarto, Supardjo MN (2013) Distribusi dan kelimpahan gastropoda pada hutan mangrove Teluk Awur Jepara. Journal of Management of Aquatic Resources 2(3): 93103

Skilleter GA and Warren S (2000) Effects of habitat modification in mangroves on the structure of mollusc and crab assemblages. 
48 JURNAL BIOSLOGOS, AGUSTUS 2017, VOL. 7 NOMOR 2

Biology and Ecology 244: 107129

Soeroyo dan Suyarso (2000) Kondisi dan inventarisasi hutan mangrove di kawasan Teluk Lampung, Pesisir dan Pantai. Puslitbang Oseanologi LIPI, Jakarta

Stiling $P$ (1992) Ecology theories and application. 2nd Edition. Prentice Hall International Inc, New York

Sulistiyowati H (2009) Biodiversitas mangrove di Cagar Alam Pulau Sempu. Jurnal Sainstek 8 (1): $56-61$

Thampanya U, Vermaat JE, Sinsakul S, Panapitukkul N (2006). and mangrove progradation of Southern Thailand. Estuarine, Coastal and Shelf Science 68: 75-85

Tomlinson PB (1986) The Botany of mangroves. Cambridge University Press. Cambridge, UK

Walters BB, Ronnback P, Kovack JM, Hussain SA, Badola R, Primavera JH, Barbier E, Guebas FD (2008). Ethnobiology, socio-economics and management of mangrove forests: A review. Aquatic Botany 89: 220-236 